\title{
A RUA COMO ESPAÇO E TEMPO DE POSSIBILIDADES EDUCATIVAS
}

\author{
Sara Ferreira de Almeida \\ DJALMA RIBEIRO JUNIOR \\ RosÂngela Pereira SoUza \\ Universidade Federal de São Carlos (UFSCar), \\ São Carlos, São Paulo, Brasil
}

\begin{abstract}
Resumo: O artigo objetiva tecer reflexões em torno da dimensão educativa da rua vivenciada por três grupos sociais marginalizados que significam esse mundo a partir de incansáveis movimentos de busca por serem mais. Visando ressaltar a possibilidade e necessidade de pesquisar com esses grupos e não sobre eles, o autor e as autoras do texto posicionam-se como educadores populares e pesquisadores que primam pelo desenvolvimento da ciência no campo da educação com compromisso social. Dessa maneira, questionam o preconceito e a indiferença voltada aos grupos populares que usam a rua como espaço de moradia, vivências afetivas e culturais, sugerindo que sejam vistos e compreendidos como produtores de práticas sociais que, por meio da arte, da comunicação, da reinvenção da moradia, do trabalho e até mesmo do uso de drogas, afirmam suas vidas e lutam pelo reconhecimento de sua humanidade.

Palavras-chave: Educação Popular. Dança de Rua. População de Rua. Usuários de Crack.
\end{abstract}

INTRODUÇÃO

Este artigo objetiva refletir sobre a dimensão educativa da rua, a partir de uma perspectiva dialética que possa subsidiar uma compreensão ampla desse espaço-tempo como catalizador de formação humana. Para tanto, partimos da questão problema "Como a rua é vista pelos sujeitos de 
nossas pesquisas?" que, acreditamos, permite a crítica ao próprio modo de produzir ciência numa perspectiva tradicionalista e funcional que vem contribuindo com a mercantilização da educação e com a instrumentalização das ciências e das instituições do conhecimento à lógica da reprodução do capital (ARROYO, 2014).

As reflexões aqui construídas partiram de nossas experiências como educador e educadoras populares, pesquisador/as no campo da educação que buscam a construção do conhecimento com e não sobre pessoas e grupos sociais que, de maneira consciente, significam a rua como espaço de convivências e de experiências relevantes à formação da vida humana. No âmbito científico, é importante apresentarmos, de partida, que tais pesquisas foram realizadas no Programa de Pós-Graduação em Educação da UFSCar, junto ao Grupo de Pesquisa Práticas Sociais e Processos Educativos que parte da compreensão de que em todas as práticas sociais é possível identificar processos educativos e que dentro destas práticas, orientamos nossos olhares, reflexões e ações para uma postura científica de unir a construção do conhecimento com o compromisso social, por entendermos ser esta uma condição ética fundamental ao quefazer científico que se une ao projeto de construção de um mundo cada vez mais justo e equânime (OLIVEIRA; SOUSA, 2014).

Organizamos este texto no intuito de apresentar como a rua é percebida pelos sujeitos das pesquisas em diálogo com os referenciais teóricos que orientam nossos trabalhos acadêmicos. Esta percepção nos indica alguns elementos estruturantes da formação humana que se dá nesse espaço-tempo que, por um lado, ajuda-nos a empreender olhar crítico sobre como a rua é vista pela sociedade mais ampla e como é sentida e vivida por quem nela está - seja por opção ou por imposições econômicas e sociais -, evidenciando-nos a dimensão educativa dessa mediação que é constituída no movimento de sujeitos que estão sendo na história.

\section{Pesquisar em COMUnhão}

As pesquisas que fazem parte deste debate foram realizadas junto com pessoas que se reconhecem como grupos sociais de: dançarinos e dançarinas de rua; pessoas que vivem e/ou moram na rua e pessoas que usufruem da rua como espaço que possibilita o uso de crack e de outras drogas. Dessa maneira, os sujeitos de nossas pesquisas significam a rua como mediação para 
moradia, trabalho, convivências e experiências diversas que as constituem como seres humanos em constante busca por serem mais.

De acordo com Paulo Freire (2005, p. 84-85), os humanos são seres para

[...] além de si mesmos - como "projetos" -, como seres a quem o imobilismo ameaça de morte; para quem o olhar para trás não deve ser uma forma nostálgica de querer voltar, mas um modo de melhor conhecer o que está sendo, para melhor construir o futuro. Daí que se identifique com o movimento permanente em que se acham inscritos os seres humanos, como seres que se sabem inconclusos; movimento que é histórico e que tem o seu ponto de partida, o seu sujeito, o seu objetivo. O ponto de partida deste movimento está nos seres humanos mesmos. Mas, como não há mulheres e homens sem mundo, sem realidade, o movimento parte das relações seres humanos-mundo. Daí que este ponto de partida esteja sempre nos homens e nas mulheres no seu aqui e no seu agora que constituem a situação em que se encontram ora imersos, ora emersos, ora insertados. Somente a partir desta situação, que lhes determina a própria percepção que dela estão tendo, é que podem mover-se. E, para fazê-lo, autenticamente, é necessário inclusive, que a situação em que estão não lhes apareça como algo fatal e instransponível, mas como uma situação desafiadora, que apenas os limita.

A rua, assim, é espaço-tempo de diversas práticas sociais e quaisquer definições deste espaço tem que levar em consideração a diversidade de perspectivas que o compõe, bem como a pluralidade cultural que o transpassa. Ou seja, a rua não é monocultural e nem estática. É local simbólico e concreto de tensões socioculturais e de (re)construções constantes da vida.

A pesquisa "Criação audiovisual na convivência dialógica em um grupo de Dança de Rua como processo de educação humanizadora" (RIBEIRO JUNIOR, 2009), realizada entre 2007 e 2009, deu-se no contexto de um processo de criação audiovisual que partiu do poder de criação e crítica dos/as jovens participantes do grupo Arte Urbana, grupo de dança de rua constituído no Jardim Cruzeiro do Sul, periferia da cidade de São Carlos/SP. Por meio de uma metodologia pautada no diálogo, na participação e no convívio, foi realizado todo um processo de pesquisa que culminou em um vídeo e uma dissertação que denunciam os preconceitos contra aqueles e aquelas que praticam a dança de rua e que a afirmam como movimento cultural, positivando a imagem dos seus praticantes perante a sociedade.

Neste contexto, em que a rua se apresenta como um espaço cultural e se manifesta como cultura, foi possível identificar, junto aos sujeitos da pesquisa, alguns valores presentes no grupo como o amor, a confiança, o respeito, 
a responsabilidade. Os participantes associaram o grupo de dança de rua a uma família que tem no diálogo e na autonomia umas das características mais marcantes. Esta experiência vivenciada com a família Arte Urbana possibilitou uma releitura da rua como espaço de cultura que traz possibilidades de se articular com dimensões mais amplas da própria formação humana (RIBEIRO JUNIOR, 2009).

Por outro lado, não podemos deixar de mencionar que há o preconceito existente contra aqueles que corporeificam certa estética da rua. Este preconceito estrutura-se a partir de uma perspectiva hegemônica em relação aos que estão na rua: a rua é vista como local perigoso e os que fazem parte deste espaço também. Este tem sido a pauta de muitos programas policiais de televisão que constroem uma imagem negativa da rua, inviabilizando uma concepção de rua como espaço de convivências de diversas culturas.

A investigação de mestrado intitulada "A prática social - Viver no Mundo da Rua - e seus processos educativos" (ALMEIDA, 2014) foi desenvolvida entre os anos de 2012 e 2014 junto à População de Rua na cidade de São Carlos/SP e se pautou nos pressupostos da educação popular e da ciência social crítica que orientam o fazer científico ao mergulho profundo na realidade concreta a ser investigada, por meio da convivência metodológica e do diálogo.

Ao se colocar lado a lado de quem vive na pele as cruezas e alegrias da vida na rua, foi possível co-responsabilizar-se e solidarizar-se com a dor do outro que enxerga e vive a rua como um campo de novas possibilidades, diferentes das anteriormente construídas quando se tinha casa. Nesse sentido, o cientista social crítico coloca-se ao lado da vítima, não somente na posição de observador participativo, mas como um militante que entra no horizonte prático da vítima e que serve por meio de um programa de investigação científico-crítico (DUSSEL, 2001).

Desse modo, foi possível coletar dados, cuja análise apontou para as categorias: 1) "As pessoas que estão na rua, não são os lixos que a sociedade joga fora"; 2) "Viver é saber viver, morar é lavar, passar, cozinhar"; 3) Viver na rua é muito difícil, mas é alegre também, sabia?"; 4) A rua é um mundo"; 5) "Na rua eu aprendo muito, experiências que eu jamais vou esquecer" e para a dimensão educativa da rua, por meio do desvelamento de seus processos educativos. A investigação demonstrou que viver na rua, ao contrário do que o senso comum afirma, é uma prática social complexa e multifacetada, não podendo ser interpretada de maneira reduzida uma vez que nela há processos que comprovam a busca incessante das pessoas por serem mais. 
Não se trata de uma prática constituída por sujeitos violentos, sujos e incultos que a degradam continuamente afetando de forma negativa o restante da sociedade. No caminhar da pesquisa, a rua foi se desvelando como mediação de múltiplos aprendizados e de elaboração de estratégias de resistência à ordem vigente. Para isso, os sujeitos que a vivificam desenvolvem processos educativos voltados à produção, reprodução e desenvolvimento da vida humana, evidenciando a existência de uma cultura de rua.

Ao desvelar os conhecimentos dessas pessoas, bem como os processos de sua produção, foi possível perceber a dialeticidade das experiências nela vivenciadas, perpassadas pela crueza da violência que se manifesta cotidianamente por meio do desprezo e da indiferença, do abandono e da dor, do frio e da fome, do crime e da morte, muitas vezes, estúpida e solitária. Nem por isso, os sujeitos que vivificam a rua deixam de buscar, incessantemente, o reconhecimento de sua humanidade, a partir de um protesto por vezes silencioso, manifestado no próprio fato de conduzirem a vida sem gozar de direitos historicamente conquistados (ALMEIDA, 2014).

A pesquisa "Educar-se entre usuários de crack" (SOUZA, 2015) foi realizada entre 2013 e 2015 com homens e mulheres em local de uso do crack conhecido como Mata do Gueto, periferia do município de Piracicaba/ SP. Partiu da compreensão do educar-se como uma construção em relações intersubjetivas do indivíduo, tomando-se como objeto de estudo, os processos educativos decorrentes da prática social do uso de crack naquele espaço público. O referencial teórico dialogou com autores da Educação Popular e da Filosofia da Libertação, tais como: Paulo Freire, Ernani Maria Fiori e Enrique Dussel e a metodologia se fundou em processos dialógicos a partir da convivência entre pesquisadora e colaboradores da pesquisa.

Foi possível desvelar nessa pesquisa, as seguintes categorias de análise construídas com seus protagonistas: Mata do Gueto; Uso do crack e"Vamos pras ideia e se correr das ideias aí o bicho pega". Foram identificados entre os/as usuários/as de crack, alguns elementos que constituem os processos educativos: respeito; boa conduta; regras; cuidados; solução de problemas e paz, todos ensinando e aprendendo, essencialmente, por meio do diálogo. Os protagonistas apontaram que a palavra vale mais que uma atitude de violência, quando argumentada e correspondida entre as pessoas que se convive. Segundo eles/as, essa é a melhor forma de ensinar e aprender. Sendo assim, seria possível anunciar que, ao utilizarem aquele espaço público para o uso de drogas, as pessoas criam possibilidades de afirmarem suas vidas, mesmo diante da calamidade ocasionada pelo uso do crack (SOUZA, 2015). 


\section{A DIMENSÃO EDUCATIVA DA RUA}

A imagem da rua construída pelos participantes do grupo de dança expressou-se, muitas vezes, sob dois significados distintos. Por um lado, a rua se configura como mediação para a expressão de um movimento cultural conhecido como Hip Hop e, como tal, é vista de forma positiva; por outro lado, a rua é sentida e concebida como espaço de violência e de risco de se entrar no mundo do crime. Estes dois sentidos, embora num primeiro momento pareçam contraditórios, foram construídos de forma complementar nas experiências de vida daqueles e daquelas que participam do grupo de dança de rua. Não foram raros os relatos dos sujeitos da pesquisa que apontaram, com pesar, a perda de um amigo ou de uma amiga que havia ingressado no mundo do crime pela porta do uso das drogas. Ao mesmo tempo, identificavam que a dança de rua se configurava como uma oportunidade de ocupar o tempo com algo que gostavam de fazer e como opção para não quererem participar de toda a rede de crimes relacionada ao comércio e uso de drogas.

A concepção de rua no contexto da dança, ao mesmo tempo em que contempla os problemas que estão relacionados a esse ambiente, também afirma a rua como mediação para a expressão artística, crítica e mobilizadora. Esta concepção parte, sobretudo, do cotidiano vivido pela juventude periférica que se defronta com as drogas e as violências presentes neste contexto. Contudo, é preciso cuidado para não confundir a rua como sendo, exclusivamente, estes problemas. O Hip Hop, de uma forma mais ampla, e a dança de rua, de uma forma mais específica, são expressões que chamam a atenção para o caráter de mediação da rua como espaço de cultura, como ambiente vivo e em movimento.

As compreensões e significados que vão sendo atribuídos pelos sujeitos que vivificam a rua emergem essencialmente de experiências coletivas, na medida em que para viver/morar na rua as pessoas necessitam estabelecer complexas redes sociais de aprendizados, não só entre seus pares, mas também com outros membros da sociedade.

Para a produção da vida na rua, os processos educativos desenvolvidos estão frequentemente ligados ao enfrentamento dos primeiros medos e desafios interpostos ao "caírem na rua". Nesse momento, desencadeiam-se processos de aceitação e compreensão da nova realidade, seguida da atribuição de sentidos que vão formatando um novo mundo. Para isso, depreendem observação atenta do entorno, seguido de contato com os mais experientes 
de rua, inaugurando processos de aprendizado, a fim de darem os próximos passos rumo à vivência no mundo da rua que se inicia (ALMEIDA, 2014, p. 139).

A partir do convívio e diálogo com a população de rua no município de São Carlos, pode-se conceber que há um aspecto comum entre as bancas - agrupamentos formados por pessoas que vivem na rua e cuja organização é feita por complexas interações entre seus membros (MARTINEZ, 2011) - que é o fato de potencializarem vivências comunitárias configurando modos específicos de ser e estar no mundo da rua. Miranda (2013 apud ALMEIDA, 2014, p. 36) explica que "[...] a rua se faz comunidade, na rua se vive comunidade. E as pessoas não entendem o que é viver comunidade na rua. Quando você fala em compartilhar comida, água, você tem isso".

Pesquisar com a População de Rua de São Carlos possibilitou a apreensão da multiplicidade de sentidos que os sujeitos imprimem ao mundo ao viverem nessa condição existencial, quando estão em permanente movimento por serem mais. Pode-se compreender que, ao "caírem na rua", fato que acontece na maior parte das vezes em função de situações difíceis vivenciadas quando estão "na casa", iniciam intensas movimentações objetivas e subjetivas, a fim de (re)construírem seus cotidianos sob nova lógica de significação que deve ser vista e interpretada com o pé na realidade tratada, de maneira dialética e não simplificada.

A Mata do Gueto está localizada entre três bairros de periferia no município de Piracicaba/SP. É um grande terreno arborizado e abandonado que antes abrigava aproximadamente cem barracos de madeira. Desde 2008, após a retirada das famílias que moravam no local pela Prefeitura, tornou-se espaço de uso do crack onde convivem homens e mulheres de faixas etárias e classes sociais distintas. Algumas pessoas que frequentam o espaço se distinguem, principalmente, pelo local de origem (outras comunidades, municípios ou estados), pela idade e pela classe social a que pertencem, mas a maioria possui semelhança em relação às histórias de vida que compartilham, assim como Rui (2012, p. 223) encontrou em sua investigação: "Históricos que mesclam pobreza, esgarçamento e rompimento dos laços familiares, empregos precários, violências cometidas ou sofridas".

Neste espaço há usuárias/os que moram em barracos improvisados espalhados pela Mata, outras/os passam o dia todo e voltam para casa à noite e ainda tem aqueles/as que permanecem apenas para fumar o crack e logo vão embora para outras comunidades. A escolha deste espaço tem significados diversos para os usuários de crack, como a possibilidade de viver 
bem, de ter tranquilidade, de encontrar felicidade, segurança e também o de viver sob constante tensão (SOUZA, 2015). De acordo com Rui (2012, p. 172) "[...] a escolha pelo espaço de uso envolve um cálculo de vantagens e desvantagens, riscos e danos, medos e necessidades, que nem sempre é simples de ser feito".

Contrariando percepções imediatistas e preconceituosas, o local de uso do crack é espaço em que as pessoas reconstroem suas vidas, vivenciam múltiplas relações como as de amizade, de afetividade, de violência, além de ser local de festividades, de realização de rodas de cantoria ou de organização de churrascos pelos próprios frequentadores da Mata do Gueto, como foi relatado por um colaborador da pesquisa, pois, assim como afirma Rui (2012, p. 223), "[...] na mesma intensidade em que se briga, também se festeja” e quando a repressão policial ameniza, torna-se possível formar uma roda de pagode. Os usuários se agrupam numa espécie de círculo (geralmente em pé), dando início à cantoria e à confraternização (SOUZA, 2015).

\section{A RUA: UM ESPAÇO-TEMPO DE POSSIBILIDADES?}

Ao contrário do que o senso comum expressado pelas mídias ou pela opinião pública afirma - de que a população de rua é constituída por pessoas loucas, sujas, vagabundas, quase animais (MATTOS; FERREIRA, 2004), de que a juventude que brinca, dança e se diverte na rua é criminosa, desocupada e sem projeto de futuro e que as pessoas que usam crack são zumbis que tornam a rua suja, degradada e perigosa - suas vozes exprimem que "não é assim!". Rafaela (apud ALMEIDA, 2014, p. 116) afirmou que "As pessoas que veem a gente na rua pensam que é só beber, usar droga, roubar. E não é! $A$ pessoa tinha que enxergar melhor". Por meio das diversas falas coletadas nas três pesquisas que vão ao encontro do que foi relatado por Rafaela, foi possível perceber que há intensos processos de afirmação da vida na rua empreendidos pelas pessoas que a vivificam em diferentes cidades brasileiras, em meio aos crescentes processos de desumanização interpostos por agentes que buscam realizar higienização social, especialmente em tempos em que a rua é tida, unicamente, como espaço de insegurança, de malandragem e de perigo iminente.

Nossos/as interlocutores/as, entretanto, afirmam que a rua é um mundo onde aprendem a viver, "tipo assim", em que você"aprende mais, sabia que você aprende mais na rua do que na escola?" (SAMARA apud ALMEIDA, 
2014, p. 135). Isso nos leva a questionar o real sentido e eficácia das políticas públicas voltadas a esses grupos sociais que acabam por reforçar a rua como espaço vazio de vivências e experiências significativas e relevantes à formação humana e à consolidação de consciência crítica em torno da realidade vivida. Assim, o presente ensaio assume uma postura crítica em relação aos discursos que justificam, banalizam ou naturalizam o fato de existirem pessoas que experienciam suas vidas, em todas as suas complexas dimensões, sem gozar de direitos humanos básicos como o do abrigo e do cuidado, naturalizando a negação da vida humana por meio de discursos reconhecidamente racionais.

A rua é local de culturas. Pelas ruas movimentam perspectivas, chocam-se ideias, tensionam-se projetos de mundo, corporificam-se mazelas e resistências. Neste espaço de culturas, diversos processos educativos vivenciados por aqueles e aquelas que estão na rua ou dela fazem parte, apontam perspectivas críticas, criativas e humanas que, em diálogo, são fundamentais para a constituição de políticas públicas que partam da cotidianidade em direção à judicialidade e não o contrário, como muitas vezes acontece.

Os "enquadros" da guarda municipal, da política civil e militar, as intervenções do poder público com internações compulsórias e as regras impostas pelas legislações em relação ao uso do álcool, de drogas ilícitas e do cigarro nos espaços públicos, perpassam os processos educativos desencadeados a partir das vivências de rua, podendo configurar uma espécie de pedagogia da violência geradora de temor e medo no outro que é visto, a priori, como marginal e transgressor (GÓNGORA, SUÁREZ, 2008). Há também a violência horizontal que coexiste com as violências institucionais e policialescas e é teorizada por Freire $(2005$, p. 55) como aquela que é concretizada no seio do próprio grupo. Segundo o autor, os oprimidos hospedam a "sombra" do opressor, sendo eles e ao mesmo tempo o outro - o opressor - e essa dualidade existencial os leva a assumirem atitudes fatalistas frente à situação concreta de opressão e também "a exercer um tipo de violência horizontal com que agridem os próprios companheiros".

Sendo o uso de crack, a vida e a dança de rua estereotipada e criminalizada em nossa sociedade e, sendo essas práticas sociais realizadas em espaços públicos, faz-se necessário empreender discussão em torno do público e do privado que se misturam e se confundem no contexto das convivências, experiências diversas, e, principalmente, na delimitação da casa e da rua empreendida pelas pessoas que nela vivenciam seus cotidianos.

Desde a sociedade feudal, a casa passou a ser o lugar de estabelecer hierarquias, regras, da individualidade, de expor opiniões, de "supercidadãos", 
ou seja, de ser (DaMATTA, 1991). Já à rua foi dada conotação negativa, sendo o lugar do anonimato, da perversão, de todos e ao mesmo tempo de ninguém, do proibido, do profano, da solidão, de rupturas, do perigo, da subversão, do coletivo, da falta de paz, do desumano, do desrespeito, da desordem, sendo problema do governo, de "subcidadãos", do não ser (SOUZA, 2015).

Para Ferreira (2001, p. 34)

[...] na rua são descarregadas as perdas causadas pelas exclusões sucessivas e, no seu oco, a ausência ou precariedade dos dispositivos de proteção à vida, construídas pela cultura ao longo do tempo: a lei, a garantia de direitos e deveres, a ciência, a saúde, lazer, trabalho, arte.

As cidades brasileiras são organizadas espacialmente e moralmente de maneira hierarquizada, "entre centro e periferia, dentro e fora" e espaços transitórios (DaMATTA, 1991, p.36). Sobre a periferia e a rua recai olhar negativo desta sociedade que as julgam como lugares da contradição, do conflito, da pobreza, ficando assim escondidas (SOUZA, 2015).

Em contraponto, nossas pesquisas mostraram que as vivências de rua se desenrolam sobre impulsos afirmativos, motivados por sentimentos que, perpassados pela esperança de sobreviver e de melhorar, movimentam as pessoas a darem continuidade as suas caminhadas pelo mundo da vida. Por vezes, a esperança é tombada por processos negativos vivenciados pela violência, pelo desprezo, pela solidão, pela indiferença, pelas privações materiais, pela dependência química e pela ausência de direitos. Porém, ao contrário de ideias preconceituosas disseminadas pelo senso comum de que na rua, quando há processos educativos, eles são somente ruins e errados, nossos interlocutores relataram a dialeticidade dos mesmos que frutificam múltiplos saberes que carregam para toda a vida, dentro ou fora da mediação da rua (ALMEIDA, 2014).

Ao viverem ou conviverem na rua, mulheres e homens, jovens e adultos resistem e lutam contra um sistema hegemônico excludente (DUSSEL, 1977) que suprime o valor de suas vidas. A partir desses modos de ser e estar no mundo, impulsionados pela própria lógica totalitária, as pessoas reinventam sua cotidianidade buscando resgatar a humanidade roubada. Dessa maneira, acreditamos que as pessoas que vivem na rua, que nela manifestam suas identidades ou que a utilizam para estabelecerem novas relações consigo mesmas, com os outros e com o mundo, organizam-se em torno de uma lógica comunitária buscando proteção, sobrevivência material e simbólica, reconhecimento de sua humanidade, aprendizados para melhor 
viver, enfim, buscam alcançar condições de vida mais digna. Nesta busca sobrevivem, resistem ao curso do projeto hegemônico de sociedade que cria um processo de desumanização da rua e que, muitas vezes, é sustentado por políticas públicas que se pautam em um discurso universalista sobre os direitos humanos, ignorando as práticas sociais vivenciadas por pessoas que procuram o ser mais no próprio espaço da rua, ignorando a rua como espaço pluricultural, tenso, dinâmico, humano.

Por fim, inscrevemos aqui nosso sonho utópico que é concreto e que compartilhamos com as pessoas que vivem, que sofrem, que brincam, que choram e que dançam na rua e que conosco dialogaram sobre a crença em dias melhores, "ressaltando que essa utopia ancora-se na esperança crítica e na história como possibilidade, pois a realidade não é, está sendo" (ALMEIDA, 2014, p. 147).

No intuito de garantir concretude a esta utopia, recomendamos, por exemplo, que os espaços formais de educação se aproximem de forma dialógica e respeitosa, das culturas que estão vivas nas ruas que os circundam. Culturas que se manifestam nas pessoas que estão na rua ou que dela fazem parte e que podem contribuir para a ressignificação de posturas e posições, assumidas ou veladas, que configuram a formação escolar. Como indicamos acima, há processos educativos presentes na rua que apontam para a construção de valores como a amizade, o respeito, a solidariedade, além de serem constituintes de uma visão crítica sobre a rua como espaço de vida, dinâmico, pluricultural e humano em constante tensão com o projeto de mundo hegemônico em curso que se sustenta na competição, no desrespeito, no individualismo.

\section{THE STREET AS SPACE AND TIME FOR EDUCATIONAL POSSIBILITIES}

ABSTRACT: The article aims to weave considerations on the educational dimension of the street lived by three marginalized social groups that give meaning to their world through untiring search to be better. Aiming the possibility and need to research with these groups and not on them, the text's authors position themselves as popular educators and researchers who care for the development of science in the field of education with social commitment. In this way, they question the prejudice and indifference 
concerning popular groups who use the street as living space, affective and cultural experiences, suggesting that they should be seen and understood as producers of social practices that, through art, communication, housing reinvention, work, and even the use of drugs, state their lives and struggle for recognition of their humanity.

KeYwords: Popular education. Street dance. Homeless. Crack users.

\section{LA CALLE COMO ESPACIO Y TIEMPO DE POSIBILIDADES EDUCATIVAS}

RESUMEN: El artículo tiene como objetivo tejer consideraciones sobre la dimensión educativa de la calle experimentada por tres grupos sociales marginados que significan ese mundo a partir de incansables movimientos de búsqueda de ser más. Con el objetivo de resaltar la posibilidad y la necesidad de investigar con esos grupos y no en ellos, el autor y las autoras del texto se posicionan como educadores populares e investigadores que priman por el desarrollo de la ciencia en el campo de una educación con compromiso social. De esa manera, cuestionar los prejuicios y la indiferencia en relación a grupos populares que utilizan la calle como espacio de habitación, experiencias afectivas y culturales, sugiriendo que sean vistos y entendidos como productores de prácticas sociales que, a través del arte, de la comunicación, de la reinvención vivienda, del trabajo e, incluso, el uso de drogas, afirman sus vidas y luchan por el reconocimiento de su humanidade.

Palabras-clave: Educación Popular. Danza de la Calle. Gente de la calle. Consumidores de crack.

\section{REFERÊNCIAS}

ALMEIDA, S. F. de. A prática social - Viver no Mundo da Rua - e seus processos educativos. 2014. 156 f. Dissertação (Mestrado em Educação) - Centro de Educação e Ciências Humanas, Universidade Federal de São Carlos, São Carlos/SP, 2014.

ARROYO, M. Outros Sujeitos, Outras Pedagogias. 2. ed. Petrópolis: Editora Vozes, 2014.

DUSSEL, E. Filosofia de la Liberación. 1. ed. México: EDICOL, 1977. Disponível em: < http://www.enriquedussel.com/libros.html>. Acesso em: 30 maio 2016.

El programa científico de investigación de Karl Marx (Ciencia funcional y critica). In: . Hacia uma filosofia politica critica. Bilbao: Ed Desclée de Brouwer, 2001.

p. 1-24. Disponível em: <http://www.enriquedussel.com/libros.html>. Acesso em: 30 maio 2016.

DaMATTA, R. A casa e a rua. 4. ed. Rio de Janeiro: Guanabara, 1991. 
FERREIRA, T. A Rua, Um Vazio Sem Borda, Ou a Instituição Dos Excluídos. Os meninos e a rua; uma interpelação à psicanálise. Editora Autêntica, FUMEC, Belo Horizonte, 2001.

FREIRE, P. Pedagogia do Oprimido. 49. ed. Rio de Janeiro: Paz e Terra, 2005.

ÓNGORA, A.; SUÁREZ, C. J. Por uma Bogotá sin mugre: violência, vida y muerte em la cloaca urbana. Universitas Humanística, Bogotá, n. 66, p. 107-138, jul./dez. 2008.

MARTINEZ, M. M. Andando e parando pelos trechos: uma etnografia das trajetórias de rua. 2011. 166 f. Dissertação (Mestrado em Antropologia Social) - Departamento de Ciências Sociais, Universidade Federal de São Carlos, São Carlos/SP, 2011.

MATTOS, R. M.; FERREIRA, R. F. Quem vocês pensam que (elas) são? - representações sobre as pessoas em situação de rua. Psicologia e Sociedade, n. 16 p. 47-58, maio/ ago. 2004.

OLIVEIRA, M. W. de; SOUSA, F. R. (Org.). Processos educativos em práticas sociais: pesquisas em educação. 1. ed. São Carlos: ED UFSCar, 2014.

RIBEIRO JUNIOR, D. Criação audiovisual na convivência dialógica em um grupo de Dança de Rua como processo de educação humanizadora. 2009. 142 f. Dissertação (Mestrado em Educação) - Centro de Educação e Ciências Humanas, Universidade Federal de São Carlos, São Carlos/SP, 2009.

RUI, T. Corpos abjetos: etnografia em cenários de uso e comércio de crack. 2012. 335 f. Tese (Doutorado em Antropologia Social) - Instituto de Filosofia e Ciências Humanas, Universidade Estadual de Campinas, Campinas/SP, 2012.

SOUZA, R. P. Educar-se entre usuários de crack. Dissertação (Mestrado em Educação) - Centro de Educação e Ciências Humanas, Universidade Federal de São Carlos, São Carlos/SP, 2015.

Sara Ferreira de Almeida: Mestre em Educação pela Universidade Federal de São Carlos (UFSCar). Doutoranda em Educação pela mesma instituição. Tem experiência e atua nos seguintes temas: educação popular, população de rua, economia solidária, incubação de cooperativas e empreendimentos populares, educação ambiental, ações socioeducativas com adolescentes.

E-mail: sarafalmeida@smail.com

DJalma Ribeiro JuniOR: Doutor em Educação pela Universidade Federal de São Carlos (UFSCar). Tem experiências nas áreas de Comunicação, Educação e Cultura, atuando principalmente nos seguintes 
temas: educação popular, comunicação popular, extensão universitária, educomunicação, gestão cultural e produção audiovisual.

E-mail:djalmacine@yahoo.com.br

Rosângela Pereira Souza: Mestre em Educação pela Universidade Federal de São Carlos (UFSCar). Tem experiência na área de Educação e Saúde, Redução de Danos, Políticas de Drogas, Psicologia Social e Docência.

E-mail: souza.rosangela@gmail.com 